\title{
FILMES BIODEGRADÁVEIS DE PROTEÍNAS DO SORO DE LEITE COM PH 6,7 COMO EMBALAGEM DE BISCOITOS
}

\author{
Alessandra Cristina Tomé ${ }^{1}$, Dayana Silva Batista Soares ${ }^{2}$, Ellen Godinho Pinto ${ }^{2}$, Taysa Martins de \\ Oliveira $^{3}$ \\ ${ }^{1}$ Tecnóloga em Alimentos do IF - Goiano-campus Morrinhos; ${ }^{2}$ Docente da área de Alimentos do IFGoiano-campus \\ Morrinhos; ${ }^{3}$ Discente do curso Superior de Tecnologia em Alimentos do IFGoiano-campus Morrinhos. E-mail: \\ dayana.soares@ifgoiano.edu.br
}

\section{RESUMO}

A embalagem tem como função principal manter a integridade do produto, protegendo-o contra danos mecânicos, perda e ganho de umidade. A maior parte das embalagens é fabricada com materiais não biodegradáveis e de fonte não renovável promovendo grande impacto ambiental. Dentre as matérias-primas empregadas na elaboração de filmes biodegradáveis encontram-se as proteínas do soro de leite. Diante disso, objetivou-se, com esse estudo, produzir filmes biodegradáveis a base de concentrado proteico de soro de leite bovino e avaliar a eficiência de aplicação desses filmes como embalagem em biscoitos. Os filmes foram elaborados pelo método de casting, e caracterizados quanto à espessura, cor, opacidade, solubilidade em água e microscopia eletrônica de varredura da superfície. Os filmes apresentaram OP $\leq 17,76 \pm 0,45, L^{*} \geq$ $81,93 \pm 0,33, a^{*} \leq 1,26 \pm 0,25, b^{*} \geq 21,70 \pm 0,95, C^{*} \geq 21,73 \pm 0,43, h^{*} \geq 1,49 \pm 0,01$ indicando serem translúcidos com coloração amarelada. As superfícies dos filmes tinham aspecto homogêneo. A solubilidade dos filmes não ultrapassou a porcentagem de $29,17 \pm 4,81$. As proteínas de soro de leite apresentaram ser uma excelente alternativa para a produção de filmes biodegradáveis.

Palavras - chave: conservação; armazenamento; concentrado proteico.

\section{BIODEGRADABLE FILMS OF PROTEINS OF MILK SERUM WITH PH 6,7 AS BISCUIT PACKAGING}

\begin{abstract}
The package's main function is to maintain the integrity of the product, protecting it from mechanical damage, loss and gain moisture. Most packaging is made of non biodegradable material and nonrenewable promoting great environmental impact. Among the raw materials used in the preparation of biodegradable films are the whey proteins. Therefore, it is aimed, with this study, produce biodegradable films protein concentrate base bovine whey and evaluate the application efficiency of these films as packaging for cookies. The films were prepared by casting method and characterized with respect to thickness, color, opacity, water solubility and scanning electron microscopy of the surface. The films had OP $\leq 17.76 \pm 0.45, L * \geq 81.93 \pm 0.33, a * \leq 1.26 \pm$ $0.25, b^{*} \geq 21.70 \pm 0.95, C^{*} \geq 21,73 \pm 0.43, h^{*} \geq 1.49 \pm 0.01$ indicating to be translucent with yellowish coloration. The surface of the films had a homogeneous appearance. The solubility of the films did not exceed the percentage of $29.17 \pm 4.81$. Whey proteins have been shown to be an excellent alternative for the production of biodegradable films.

Key - words: conservation; storage; protein concentrate.
\end{abstract}




\section{INTRODUÇÃO}

A indústria de alimentos tem, ao longo do tempo passado por constantes mudanças para se adaptar às crescentes exigências dos consumidores. A demanda por produtos com uma longa vida de útil, estabelece novos requisitos às embalagens (AZEREDO, 2012).

O desenvolvimento de embalagens comestíveis e biodegradáveis tem merecido atenção dos pesquisadores durante as últimas décadas, que vêm estudando novos materiais provenientes de fontes renováveis como alternativa às embalagens plásticas sintéticas (AZEREDO, 2012).

As embalagens são de fundamental importância na comercialização dos produtos uma vez que desempenham a função básica de proteção. Além desta função, também são apoio ao marketing do produto, agregando valor a este e estimulando sua venda (ABRE, 2011).

Filmes biodegradáveis são películas obtidas a partir de materiais biodegradáveis e apresentam a função de proteger os produtos quanto às ações externas (KROCHTA, 2002).

Filmes e coberturas proteicas podem atuar como barreira semipermeável à umidade, gases e compostos aromáticos, controlando a transferência de massa (umidade, oxigênio, dióxido de carbono, lipídio) em sistemas alimentícios, mantendo a integridade estrutural e características de manuseio, retendo compostos aromáticos voláteis e servindo de veículos para aditivos (YOSHIDA, 2002).

As características de um filme estão relacionadas à estrutura química do polímero, natureza do solvente, presença de aditivos, como agentes de ligações cruzadas, e condições do meio durante sua produção (GONTARD et al., 1994).

A escolha do polímero está intimamente relacionada ao tipo de produto a ser embalado, ou seja, deve-se escolher um polímero que possua capacidade de proteção suficiente para manter a integridade do produto sem alterar suas características (GALLO et al., 2000).

Os filmes e coberturas comestíveis baseados em proteínas do leite, por exemplo, apresenta um excelente valor nutricional, um potencial crescente em sua aceitação e amplo uso dos produtos lácteos (SABATO, 2000). Filmes proteicos de soro de leite também apresentam um grande potencial para aplicação como embalagem, evidenciando suas propriedades mecânicas e ópticas (FERNANDES et al., 2015).

Os filmes proteicos podem ser utilizados como um complemento à embalagem sintética, prolongando a vida-de-prateleira garantindo maior qualidade do produto final, além de apresentar um potencial econômico, pois sua matéria-prima é de baixo custo. Porém, a natureza hidrofílica dos filmes proteicos limita a sua aplicação em produtos que requerem barreira à umidade (YOSHIDA; ANTUNES, 2009).

As proteínas do soro de leite são importantes polímeros empregados na elaboração de filmes biodegradáveis transparentes e flexíveis, com boas propriedades de barreira ao oxigênio (RAMOS et al., 2013). O soro de leite bovino é um importante co-produto da indústria do queijo, variando suas características de acordo com a qualidade do leite e tipologia de processamento (SMITHERS, 2008).

O objetivo desse estudo foi produzir filmes biodegradáveis à base de proteína de soro de leite e avaliar a eficiência da aplicação desses filmes como embalagem para biscoitos tipo água e sal.

\section{MATERIAL E MÉTODOS}

O experimento foi realizado no laboratório do Setor de Agroindústria, do Instituto Federal Goiano Campus Morrinhos, localizado na cidade de Morrinhos (GO). Os filmes foram obtidos a partir de concentrado proteico de soro de leite comercial (Lacprodan 80), fornecido pela indústria Arla Foods Ingredientes SA (Argentina). O teor de proteínas do concentrado proteico foi determinado segundo método de micro-kjeldahl (AOAC, 2012). 
Os filmes foram produzidos pelo método de casting, segundo Soares (2012) com adaptações. Soluções filmogênicas aquosas foram preparadas contendo $5 \%$ de proteínas, 3,75\% de glicerol e $91,25 \%$ de água, havendo a total solubilização das proteínas na água destilada e posterior adição do glicerol. Em seguida, as soluções foram aquecidas a $90{ }^{\circ} \mathrm{C}$ por 30 minutos em banho-maria (Quimis, mod. Q334M Diadema, São Paulo, Brasil) e resfriada em banho de gelo, aplicando-se agitação moderada, ate atingir 26 ㄷ. $\mathrm{O}$ pH da solução foi ajustado em pHmetro (Tecnopon, Piracicaba, São Paulo, Brasil) para 6,7 (pH natural do leite) posteriormente, alíquotas de solução filmogênica foram dispersas em placas de vidro encapadas com plástico adesivo (12 $\mathrm{x}$ $12 \mathrm{~cm}$ ). A espessura foi controlada pelo volume disperso em cada placa. A solução foi seca em temperatura de $26 \stackrel{\circ}{\circ}$ por 36 horas.

Os filmes foram removidos das placas de vidro, identificados e levados para armazenamento por 72 horas em dessecadores a umidade relativa de $52 \%$ (solução super saturada de nitrato de magnésio) e temperatura de $25 \pm 1{ }^{\circ} \mathrm{C}$ para uniformizar seu conteúdo de umidade até o momento das análises.

A eficiência da aplicação dos filmes à base de proteínas de soro de leite foi avaliada em um sistema de embalagem utilizando uma seladora (Max Machine, Atibaia, São Paulo, Brasil) para vedação das laterais dos filmes contendo amostras de biscoito. Os biscoitos foram armazenados à temperatura ambiente de $26{ }^{\circ} \mathrm{C}$ por 5 dias. Os filmes foram avaliados periodicamente, a cada 24 horas, durante o armazenamento quanto à solubilidade em água, cor, opacidade e microscopia eletrônica de varredura da superfície. $O$ tratamento $T_{0}$ corresponde ao filme não armazenado (controle), $\mathrm{T}_{1}$ com 24 horas de armazenamento, $\mathrm{T}_{2}$ com 48 horas de armazenamento, $\mathrm{T}_{3}$ com 72 horas de armazenamento e $\mathrm{T}_{4}$ com 96 horas de armazenamento.

A espessura dos filmes foi obtida através da média dos valores de seis pontos aleatórios em diferentes segmentos do filme, utilizando-se micrômetro (Insize, 3210-25, China, resolução 0,001 $\mathrm{mm})$.

A cor dos filmes foi medida em colorímetro de bancada (Hunter Associates Laboratory Inc -

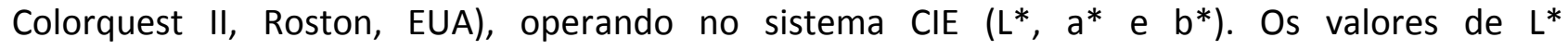
(luminosidade), a* (intensidade da cor verde a vermelho) e b* (intensidade da cor amarela a azul) e a opacidade foram obtidos depois da calibração do equipamento (padrão branco e preto), utilizando o software Universal v 3.6 (Hunter Lab, EUA). Foram realizadas 12 leituras de cada tratamento.

Também foram calculados o índice croma $\left(C^{*}\right)$, considerado o atributo quantitativo de cor e hue $\left(h^{*}\right)$, em radianos, considerado o atributo qualitativo de cor.

A solubilidade em água dos filmes foi determinada segundo Gontard, et. al (1994) onde porções de filmes de $28 \mathrm{~mm}$ de diâmetro foram secos em estufa (Icamo, Mod. 01, Rio de Janeiro, Brasil) à 105 C por 24 horas para determinação da matéria seca inicial dos filmes. Após a primeira pesagem as amostras foram imersas em recipientes com $50 \mathrm{~mL}$ de água destilada e agitadas lentamente por 24 horas (25 ㄷ) em homogeneizador de soluções (Phoenix - AP 32 - 09076, Araraquara, Brasil). Após este período, as amostras foram removidas e secas em estufa (Icamo, Mod. 01, Rio de Janeiro, Brasil) à 105 C por 24 horas para determinar a massa de matéria seca que não dissolveu em água. O percentual de solubilidade dos filmes foi determinado como porcentagem de matéria seca solubilizada.

A análise de Microscopia Eletrônica de Varredura da superfície foi realizada no laboratório Multiusuário de Microscopia de Alta Resolução (LabMic) do Instituto de Física da Universidade Federal de Goiás (Goiânia/GO).

Para a realização da análise, as amostras foram colocadas em dessecadores sob vácuo com sílica-gel (0\% UR) durante 7 dias para eliminar resíduos de umidade. As amostras a serem analisadas foram montadas em suporte de alumínio ou "stubs" com fita adesiva dupla-face, em seguida, foram colocadas em câmara metalizadora (SCO -040 Marca Balzers), para serem 
revestidas com uma camada de ouro. A microscopia eletrônica de varredura da superfície, foi realizada no microscópio eletrônico (JEOL - JSM 6610, Tokyo, Japão), utilizando-se um acelerador de voltagem de $2,5 \mathrm{kV}$.

Durante o período de armazenamento, o teor de umidade dos biscoitos foi medido pela porcentagem da perda de massa após a secagem em uma estufa à temperatura de $105^{\circ} \mathrm{C}$ a cada 24 horas (IAL, 2004).

A análise estatística dos resultados foi efetuada usando ANOVA e a comparação entre as médias das análises foi realizada pelo teste de Tukey $(p \leq 0,05)$. Utilizando o programa ASSISTAT versão 7.7 beta (SILVA; AZEVEDO, 2016).

\section{RESULTADOS E DISCUSSÕES}

O concentrado proteico de soro de leite apresentou teor de proteínas de $72,70 \pm 0,48$, valor este que se enquadra nas faixas de concentrados proteicos (CPS).

Os concentrados proteicos de soro de leite (CPS) podem variar sua composição de proteínas de 35 a $80 \%$ e os isolados proteicos de soro de leite (IPS) devem apresentar valores superiores a $90 \%$ de proteínas. Quando CPS contém, em média, 53\% de proteínas terão em torno de $35 \%$ de lactose, $5 \%$ de gordura e $7 \%$ de cinzas. Quando a concentração de proteínas aumenta para $80 \%$, o conteúdo de lactose diminui, ficando em média $7 \%$, gordura e cinzas entre 4 e $7 \%$ (ANTUNES, 2003; HUFFMAN, 1996). Esta variação na composição pode ser explicada pelas diferenças na composição inicial do soro, que depende da composição do leite e, sobretudo, dos processos de obtenção de queijos ou caseínas (DE LA FUENTE et al., 2002).

A espessura média dos filmes foi de $0,1181 \pm 0,008 \mathrm{~mm}$. $O$ controle da espessura dos filmes é importante para se avaliar a uniformidade dos materiais, a recorrência da medida de suas propriedades, bem como a legitimidade das comparações entre filmes. A variação da espessura dos filmes pode estar relacionada com possíveis variações nas propriedades dos filmes (OLIVEIRA et al., 1996).

O aspecto visual está relacionado com a cor e transparência final dos filmes proteicos, e é um dos principais atributos de qualidade que afeta a percepção do consumidor que possui uma posição relevante na aceitação alimentar (YOSHIDA, 2002).

Os valores médios dos parâmetros de cor (Opacidade, $L^{*}, a^{*}, b^{*}, C^{*}, h^{*}$ ) dos filmes biodegradáveis estão apresentados na Tabela 1. 
Tabela 1. Parâmetros de cor (OP, $\left.L^{*}, a^{*}, b^{*}, C^{*}, h^{*}\right)$ de filmes biodegradáveis de proteínas do soro de leite.

\begin{tabular}{|c|c|c|c|c|c|}
\hline Parâmetros & Tratamen & & & & \\
\hline & $\mathrm{T}_{0}$ & $\overline{T_{1}}$ & $\overline{T_{2}}$ & $\mathrm{~T}_{3}$ & $\mathrm{~T}_{4}$ \\
\hline OP & $18,76^{\mathrm{a}^{*}} \pm 0,45$ & $17,06^{b} \pm 0,26$ & $16,13^{c} \pm 0,37$ & $16,19^{c} \pm 0,35$ & $15,46^{d} \pm 1,52$ \\
\hline$L^{*}$ & $82,11^{a} \pm 0,51$ & $82,41^{a} \pm 0,20$ & $82,25^{\mathrm{a}} \pm 0,46$ & $81,93^{a} \pm 0,33$ & $82,01^{a} \pm 1,33$ \\
\hline$a^{*}$ & $1,26^{\mathrm{a}} \pm 0,26$ & $0,93^{b} \pm 0,23$ & $0,92^{b} \pm 0,23$ & $1,00^{\mathrm{ab}} \pm 0,38$ & $1,06^{\mathrm{ab}} \pm 0,68$ \\
\hline$b^{*}$ & $21,70^{a} \pm 0,95$ & $23,49^{b} \pm 0,40$ & $23,18^{b} \pm 0,90$ & $24,10^{b} \pm 0,60$ & $23,35^{b} \pm 1,67$ \\
\hline$C^{*}$ & $21,73^{a} \pm 0,43$ & $23,50^{\mathrm{b}} \pm 0,93$ & $23,41^{b} \pm 0,78$ & $24,27^{b} \pm 0,84$ & $24,17^{b} \pm 0,78$ \\
\hline$h^{*}$ & $1,49^{\mathrm{a}} \pm 0,01$ & $1,52^{\mathrm{b}} \pm 0,01$ & $1,52^{\mathrm{b}} \pm 0,01$ & $1,52^{\mathrm{b}} \pm 0,01$ & $1,52^{\mathrm{b}} \pm 0,02$ \\
\hline
\end{tabular}

*Letras minúsculas indicam diferença significativa $(p<0,05)$ entre tratamentos.

Os filmes apresentaram valores elevados de luminosidade $\left(L^{*} \geq 81,931\right)$, demonstrando que são de coloração clara (Tabela 1). Os resultados estão em concordância com Yoshida (2002) que obteve valores de $L^{*} \geq 83,680$ em filmes proteicos de soro de leite. Os filmes apresentaram-se translúcidos, evidenciando valores baixos de opacidade (OP $\leq 18,76)$. O trabalho está em concordância com Soares (2012) e Fernandes (2014) que também obtiveram filmes translúcidos de proteínas do soro de leite apresentando valores elevados de luminosidade $L^{*}$ de 85,38 e opacidade $\leq 17,67, L^{*} \geq 87,80$ e opacidade $\leq 22,04$, respectivamente. Segundo Vicentini (2003), a luminosidade $L^{*}$ representa a terceira dimensão da cor, sendo a qualidade pela qual se distingue uma cor clara de uma escura.

Os valores de croma a* próximos a 0 (Tabela 1) indicam que os filmes não apresentaram tendência as cores verde e vermelha. Os valores de $b^{*}$ (Tabela 1 ) indicam que os filmes apresentaram coloração amarelada.

Os índices croma e hue relacionam os valores de $a^{*}$ e $b^{*}$ para melhor avaliação dos resultados. O índice hue variou entre 1,49 e 1,52 rad, indicando que os filmes apresentam cor amarela. Os valores do índice croma foram aumentados com o armazenamento. Segundo Granato e Masson (2010), quanto maior os valores de croma, maior é a intensidade da cor das amostras percebidas pelos seres humanos, como isso, a maior intensidade de cor foi mais percebida nos filmes de três dias de armazenagem. A coloração e a opacidade dos filmes não devem ser alteradas ao longo do armazenamento do material, uma vez que essa mudança de aspecto pode prejudicar a aceitação do produto que foi adicionado do filme (SAKANAKA, 2007).

Segundo Gontard, Guilbert e Cuq (1992), a solubilidade em água e uma importante propriedade dos filmes comestíveis, tanto nas suas aplicações, como na proteção dos alimentos onde a atividade de água é alta, ou ainda quando o filme entra em contato com a água durante o processamento do alimento embalado.

Os valores médios de solubilidade em água de filmes biodegradáveis a base de proteínas do soro de leite estão apresentados na Tabela 2. 
Tabela 2. Valores médios de solubilidade (\%) em água de filmes biodegradáveis a base de proteínas do soro de leite utilizadas no armazenamento de biscoitos.

\begin{tabular}{ccccc}
\hline \multicolumn{5}{c}{ Solubilidade em água (\%) } \\
\hline $\mathrm{T}_{0}$ & $\mathrm{~T}_{1}$ & $\mathrm{~T}_{2}$ & $\mathrm{~T}_{3}$ & $\mathrm{~T}_{4}$ \\
\hline $29,17^{\mathrm{a}} \pm 4,81$ & $23,33^{\mathrm{a}} \pm 0,00$ & $22,50^{\mathrm{a}} \pm 2,89$ & $24,58^{\mathrm{a}} \pm 2,89$ & $22,50^{\mathrm{a}} \pm 2,89$ \\
\hline
\end{tabular}

*Letras minúsculas indicam diferença significativa $(p<0,05)$ entre os tratamentos.

McHugh e Krochta (1994); Fairley et al. (1996) e Galietta et al. (1998) afirmaram que filmes proteicos a base de proteínas do soro de leite são parcialmente insolúveis em água devido a presença de ligações dissulfidicas intermoleculares. O presente trabalho está em concordância com os autores, uma vez que as amostras, após o período de armazenamento, mantiveram-se integras, sem nenhuma deformação aparente (Tabela 2).

Estudos que envolvem a avaliação de filmes comestíveis e/ou biodegradáveis utilizam o microscópio eletrônico de varredura como ferramenta, buscando correlacionar as propriedades dos mesmos com sua estrutura morfológica (DE SOUZA, 2001).

A partir da microscopia eletrônica de varredura torna-se possível a visualização de possíveis imperfeições, presença de poros, separação dos componentes utilizados na formulação dos filmes e a estrutura da superfície do material (BATISTA, 2004).

Pela Figura 1 observa-se que os filmes apresentam estrutura homogênea. Observou-se a presença de micro-poros no tratamento $T_{3}$. Aparentemente não se observou efeito do período de armazenamento na microscopia eletrônica dos filmes.

Figura 1. Microscopia eletrônica de varredura da superfície de filmes biodegradáveis de proteínas do soro de leite utilizados no armazenamento de biscoitos.

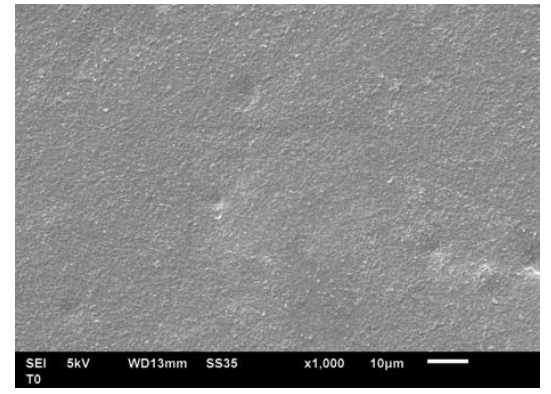

$\mathrm{T}_{0}$

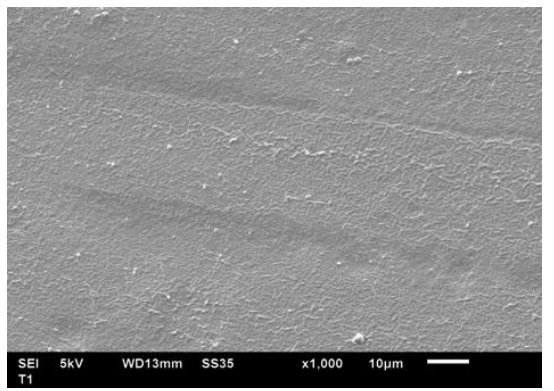

$\mathrm{T}_{1}$

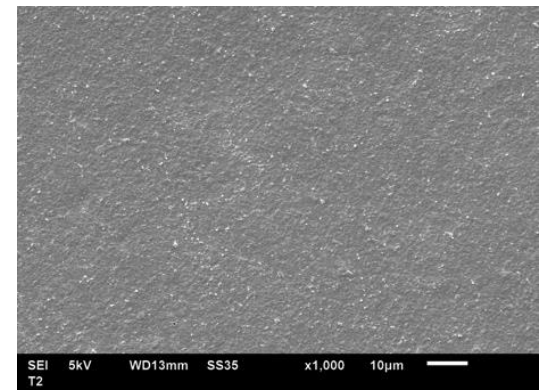

$\mathrm{T}_{2}$

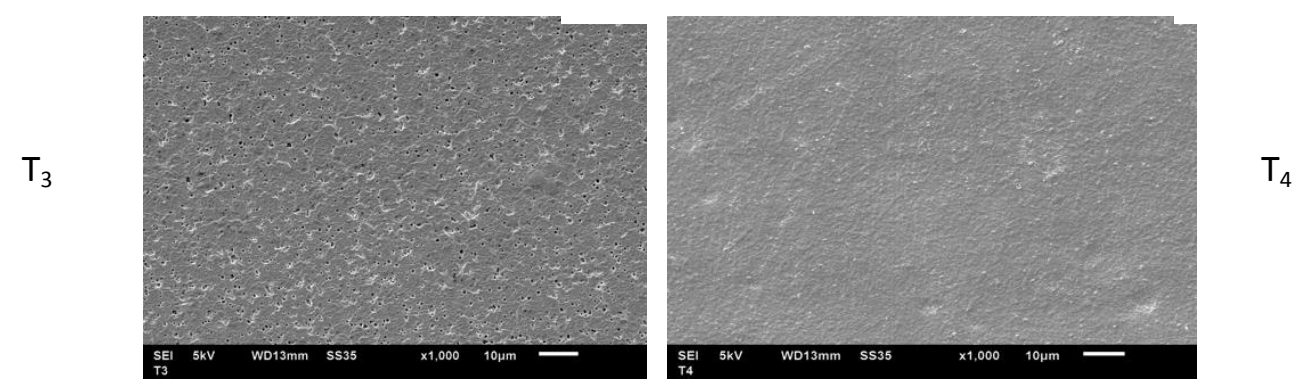

Durante o armazenamento observou-se o ganho de massa dos biscoitos durante após o primeiro dia de armazenamento. Após este período não observou diferença significativa $(p \leq 0,05)$ entre os resultados (Tabela 3 ). Aparentemente a textura dos biscoitos não sofreu alteração após o acondicionamento. 
Tabela 3. Valores médios de umidade (\%) dos biscoitos armazenados em filmes biodegradáveis a base de proteínas do soro de leite.

\section{Umidade (\%) dos biscoitos armazenados}

\begin{tabular}{ccccc}
\hline $\mathrm{T}_{0}$ & $\mathrm{~T}_{1}$ & $\mathrm{~T}_{2}$ & $\mathrm{~T}_{3}$ & $\mathrm{~T}_{4}$ \\
\hline $3,49^{\mathrm{a}^{*}} \pm 0,66$ & $7,16^{\mathrm{b}} \pm 1,05$ & $9,49^{\mathrm{b}} \pm 0,31$ & $7,88^{\mathrm{b}} \pm 0,57$ & $9,09^{\mathrm{b}} \pm 0,57$ \\
\hline
\end{tabular}

* Letras minúsculas indicam diferença significativa $(p<0,05)$ entre os tratamentos.

O aumento do teor de umidade pode ser justificado pela alta permeabilidade ao vapor de água apresentado pelos filmes à base de proteínas do soro de leite, uma vez que durante o período de armazenamento a umidade relativa do ar manteve-se acima de $60 \%$. Com isso, os filmes de proteínas do soro de leite são indicados como embalagens primárias aos alimentos.

Yoshida e Antunes (2009) avaliaram a eficiência da aplicação de filmes à base de proteínas de soro de leite em um sistema de embalagem que consistia em um pote plástico utilizando-se filmes de proteínas de soro de leite como fechamento superior. Estes autores reportaram que os filmes apresentaram uma barreira moderada à umidade.

\section{CONCLUSÃO}

As proteínas do soro de leite representam uma boa alternativa de matéria-prima na elaboração de filmes biodegradáveis.

Mesmo utilizando o método casting para a elaboração dos filmes, não houve uma elevada variação na espessura dos filmes, o que facilitou a avaliação da uniformidade dos materiais. Os filmes apresentaram-se translúcidos e de coloração amarelada. Não se verificou variação na solubilidade dos filmes durante o armazenamento. As imagens de microscopia indicaram filmes com aparência homogênea.

Houve ganho de massa dos biscoitos durante o primeiro dia de armazenagem indicando que os filmes biodegradáveis de proteínas do soro de leite podem ser utilizados em alimentos de baixa umidade armazenados em ambientes de baixa umidade relativa do ar.

\section{REFERÊNCIAS}

ABRE. Associação Brasileira de Embalagens. Dados de mercado 2011. Disponível em: <http://www.abre.org.br/centro_dados.php>. Acesso em: 05 fev. 2017.

ANTUNES, A. J. Funcionalidade de proteínas do soro de leite bovino. Barueri: Manole, 2003. 135p.

ASSOCIATION OF OFFICIAL ANALYTICAL CHEMISTS. Official methods o analysis. 15. ed. Arlington: AOAC, 1990.

AZEREDO, H. M. C.; Fundamentos de estabilidade de alimentos. Editora técnica. 2a Ed. Ver. Ampl. - Brasilia, DF; Embrapa, 2012.

BATISTA, J.A. Desenvolvimento, Caracterização e Aplicações de Biofilmes a Base de Pectina, Gelatina e Ácidos Graxos em Bananas e Sementes de Brócolos. 2004, 140f. Dissertação (Mestrado em Engenharia de Alimentos) - Faculdade de Engenharia de Alimentos, Universidade Estadual de Campinas, Campinas.

DE SOUZA, S M A. Elaboração e caracterização de filmes comestíveis biodegradáveis a base de proteínas miofibrilares bovina. 2001, 207f. Tese (Doutorado em Engenharia de Alimentos) Faculdade de Engenharia de Alimentos, Universidade Estadual de Campinas, Campinas. 
FARLEY, P.; MONAHAN, F. J.; GERMAN, B. B.; KROCHTA, J. M. Mechanical properties and water vapor permeability of edible films from whey protein isolate and $\mathrm{N}$-ethylmaleimide or cysteine. Journal of Agricultural and Food Chemistry, Whashington, v. 44, n. 12, p. 3789-3792, 1996.

de la FUENTE, M. A.; HEMAR, Y.; TAMEHANA, M.; MUNRO, P. A.; SINGH, H. Process-induced changes in whey proteins during the manufacture of whey protein concentrates. International Dairy Journal, Oxfod, v. 12, n.4, p. 361-369, 2002.

FERNANDES, A. P. S.; Avaliação e caracterização das propriedades filmogênicas de proteínas do soro de leite submetidas à irradiação e modificação de pH. 2014. 98 f. Dissertação (Mestrado em Ciência e Tecnologia de Alimentos) - Escola de Agronomia e Engenharia de Alimentos, Goiânia.

FERNANDES, A. P. S.; COSTA, J. B.; SOARES, D. S. B.; MOURA, C. J. DE; SOUZA, A. R. M. DE. Application of biodegradable films produced from irradiated whey protein concentrate. Pesquisa Agropecuária Tropical, Goiânia, v. 45, n. 2, p. 192-199, 2015. https://doi.org/10.1590/1983$\underline{40632015 \mathrm{v} 4530844}$

GALIETTA, G.; GIOIA, L.; GUILBERT, S.; CUQ, B. Mechanical and thermomachanical properties of film base don whey proteins as affected by plasticizer and crosslinking agents. Journal of Dairy Science, Savoy, v. 81, n. 12, p. 3123-3130, 1998.

GALLO, J-A. Q.; DEBEAUFORT, F.; CALLEGARIN, F.; VOILLEY, A. Lipid hydrophobicity, physical state and distribution effects on the properties of emulsion-based films. Journal of Membrane Science, Amsterdan, v.180, n.1, p.37- 46, 2000.

GRANATO, D.; MASSON, M. L. Instrumental color and sensory acceptance of soy-based emulsions: a response surface approach. Ciência e Tecnologia de Alimentos. Campinas, vol. 30, n. 4, p. 10901096, 2010.

GONTARD, N.; DUCHES, C. CUQ, J. L.; GUILBERT, S. Edible composite films of wheat gluten and lipids water vapor permeability and other physical properties. International Journal of Food Science and Technology, Malden, v.29, n.1, p.39-50, 1994.

GONTARD, N.; GUILBERT, S.; CUQ, J.L. Edible wheat gluten films: Influence of the main process variables on film properties using response surface methodology. Journal of Food Science, v.57, n.1, p. 190-195, 1992.

HUFFMAN, L. M. Processing whey protein for use as a food ingredient. Food Technology, Chicago, v. 50, p. 49-52, 1996.

KROCHTA, J. M. Protein as raw materials for films and coatings: definitions, status, and opportunities. In: GENNADIOS, A. Protein-based films and coating. New York: CRC Press, p. 1-39, cap. 1, 2002.

LUTZ, I. A. Normas Analíticas do Instituto Adolfo Lutz. Métodos químicos e físicos para análise de alimentos. v. 1, 4. ed. São Paulo: Inst. Adolfo Lutz, 2004.

McHUGH, T. H.; AUJARD, J. F.; KROCHTA, J. M. Plasticized whey-protein edible films water-vapor permeability properties. Journal of Food Science, Chicago, v. 59, n. 2, p. 416- 420, 1994. 
OLIVEIRA, L. M.; SARANTÓUPOLOS, C. I. G. L.; CUNHA, D. G.; LEMOS, A. B. Ensaios para avaliação de embalagens plásticas flexíveis. Campinas: Centro de Tecnologia de Embalagem, 1996.

RAMOS, O. L.; PREIRA R. N.; RODRIGUES R. TEIXEIRA J.A.; VICENTE A. A.; MALCATA F.X. Effect of whey protein purity and glycerol content upon physical properties of edible films manufactured therefrom. Food Hydrocolloids, v. 30, n. 1, p. 110-122, 2013.

SABATO, S. F.; Aplicação da irradiação na formação de filmes comestíveis protéicos. 2000. $107 f$. Tese (Doutorado em Ciências na Área de Tecnologia Nuclear) - Instituto de Pesquisas Energéticas e Nucleares. Autarquia associada à Universidade de São Paulo, São Paulo.

SAKANAKA, L. S. Confecção de filmes biodegradáveis por extrusão de blendas de amido termoplástico e polibutileno succinato co-adipato (PBSA). 2007. 123f. (Tese de Doutorado Universidade Estadual de Londrina, Londrina.

SILVA, F. A. S.; AZEVEDO, C. A. V. (2016). The Assistat Software Version 7.7 and its use in the analysis of experimental data. African Journal of Agricultural Research, v. 11, n. 39, p. 3733-3740, 2016. http://dx.doi.org/10.5897/AJAR2016.11522.

SOARES, D. S. B. Influência do pH e da irradiação em filmes biodegradáveis de proteínas do soro de leite. 2012. 90f. Dissertação (Mestrado em Ciência e Tecnologia de Alimentos) - Universidade Federal de Goiás Escola de Agronomia e Engenharia de Alimentos, Goiânia.

SMITHERS, G. W. Whey and whey proteins - from 'gutter-to-gold'. International Dairy Journal, Alberta, v. 18, n. 7, p. 695-704, 2008.

VICENTINI, N. M. Elaboração e caracterização de filmes comestíveis à base de fécula de mandioca para uso em pós-colheita. 2003. 62f. Tese (Doutorado em Agronomia) - Faculdade de Ciências Agronômicas da Unesp, São Paulo.

YOSHIDA, C. M. P. Aplicação de concentrado proteico de soro de leite bovino na elaboração de filmes comestíveis. 2002. 246f. Tese (Doutorado em Alimentos e Nutrição) - Universidade Estadual de Campinas, Campinas-SP.

YOSHIDA, C. M. P.; ANTUNES, A. J. Aplicação de filmes proteicos a base de soro de leite. Ciência e Tecnologia de Alimentos, Campinas, v.29, n.2, p. 420, 2009. 